\title{
Pre- and Postnatal Maturation are Important for Fentanyl Exposure in Preterm and Term Newborns: A Pooled Population Pharmacokinetic Study
}

\author{
Yunjiao Wu ${ }^{1}$ - Swantje Völler ${ }^{1,2,3} \cdot$ Robert B. Flint $^{3,4} \cdot$ Sinno H. P. Simons ${ }^{3} \cdot$ Karel Allegaert $^{4,5} \cdot$ Vineta Fellman $^{6,7,8}$. \\ Catherijne A. J. Knibbe ${ }^{1,3,9}$
}

Accepted: 14 September 2021 / Published online: 13 November 2021

(c) The Author(s) 2021

\begin{abstract}
Background and Objective Fentanyl is an opioid commonly used to prevent and treat severe pain in neonates; however, its use is off label and mostly based on bodyweight. Given the limited pharmacokinetic information across the entire neonatal age range, we characterized the pharmacokinetics of fentanyl across preterm and term neonates to individualize dosing.

Methods We pooled data from two previous studies on 164 newborns with a median gestational age of 29.0 weeks (range 23.9-42.3), birthweight of $1055 \mathrm{~g}$ (range 390-4245), and postnatal age (PNA) of 1 day (range 0-68). In total, 673 plasma samples upon bolus dosing ( 69 patients; median dose $2.1 \mu \mathrm{g} / \mathrm{kg}$, median 2 boluses per patient) or continuous infusions (95 patients; median dose $1.1 \mu \mathrm{g} / \mathrm{kg} / \mathrm{h}$ for $30 \mathrm{~h}$ ) with and without boluses were used for population pharmacokinetic modeling in NONMEM ${ }^{\circledR} 7.4$.

Results Clearance in neonates with birthweight of 2000 and $3000 \mathrm{~g}$ was 2.8- and 5.0-fold the clearance in a neonate with birthweight of $1000 \mathrm{~g}$, respectively. Fentanyl clearance at PNA of 7, 14, and 21 days was 2.7-fold, 3.8-fold, and 4.6-fold the clearance at 1 day, respectively. Bodyweight-based dosing resulted in large differences in fentanyl concentrations. Depending on PNA and birthweight, fentanyl concentrations increased slowly after the start of therapy for both intermittent boluses and continuous infusion and reached a maximum concentration at $12-48 \mathrm{~h}$.

Conclusions As both prenatal and postnatal maturation are important for fentanyl exposure, we propose a birthweight- and PNA-based dosage regimen. To provide rapid analgesia in the first $24 \mathrm{~h}$ of treatment, additional loading doses need to be considered.
\end{abstract}

\section{Introduction}

Neonates frequently experience repetitive or prolonged pain in neonatal intensive care units (NICUs), where they undergo many diagnostic, surgical, and therapeutic procedures [1]. Until the late 1980s, it was widely unrecognized that neonates may be capable of perceiving pain [2]. Nowadays, evidence suggests that neonates are more sensitive to pain than adults [3], and insufficient pain treatment in neonates is associated with short-term complications and long-term problems in cognitive and motor development [4, 5]. Opiates have become the mainstay analgesia in the NICU for the treatment of severe pain. Compared with morphine, fentanyl has advantages such as a faster onset, less histamine

Catherijne A. J. Knibbe

c.knibbe@antoniusziekenhuis.nl

Extended author information available on the last page of the article release, and minimal effect on hemodynamics $[6,7]$. Therefore, it is used for neonates undergoing mechanical ventilation and extracorporeal membrane oxygenation therapy $[8$, 9] and to provide rapid and strong analgesia during and after painful procedures and surgeries $[6,10]$. Despite the widespread use of fentanyl in neonates, it has not been formally approved for this population. Although most guidelines recommend bodyweight-based dosing $[1,11]$ for neonates, these dosage regimens do not consider the fast nonlinear developmental changes on drug disposition in early life [12] and may not be optimal for neonatal use.

In adults, fentanyl is a high extraction-ratio drug that is primarily metabolized in the liver through $N$-dealkylation via cytochrome P450 3A4 (CYP3A4). Only a small fraction of fentanyl is excreted unchanged in the urine [13, 14]. Neonates have lower hepatic blood flow and CYP3A4 activity than adults [15-18], which may lead to immature fentanyl clearance and metabolism in neonates. In addition, during the first days and months of life, neonatal physiology 


\section{Key Points}

Published neonatal pharmacokinetic studies showed large variability in fentanyl pharmacokinetics; however, this variability has not been extensively quantified throughout different gestational and postnatal ages.

This population pharmacokinetic study indicated that a large extent of this pharmacokinetic variability in preterm and term newborns could be attributed to both prenatal (birthweight) and postnatal (postnatal age) patient characteristics.

The common practice of bodyweight-based dosing results in varying concentrations over time across newborns. A comparable exposure can be achieved by postnatal- and birthweight-based dosage regimens.

Fentanyl concentrations increase slowly after continuous infusion begins. Additional loading doses need to be considered to provide rapid analgesia in the first $24 \mathrm{~h}$ of treatment.

undergoes major age-related changes [19]. As a result, in the newborn population, clearance may be influenced by differences in prenatal and postnatal maturation, resulting in extensive intra- and interpatient variability in pharmacokinetic profiles [20].

Previous pharmacokinetic reports have attributed the variability in fentanyl clearance to birthweight (BW), gestational age (GA), current bodyweight $(\mathrm{CW})$, and postnatal age (PNA) [21, 22]. Nevertheless, because of the limited number of patients included in earlier research, and the fact that few authors used a population pharmacokinetic approach, the exact influence of these factors remains to be identified and quantified throughout different GA and PNA [23]. Population pharmacokinetic analysis techniques are well capable of dealing with sparse sampling in neonates and at the same time explaining and quantifying the variability between patients [24, 25]. Until now, only one population pharmacokinetic study that included neonates with a GA $<32$ weeks was performed that indicated that fentanyl clearance was related to both PNA and GA [26]. Because this study only included very preterm neonates with GA $<32$ weeks, whether this relationship also holds true for less preterm and term neonates remains unclear.

The aim of this study was to develop a pooled population pharmacokinetic study to characterize fentanyl pharmacokinetics in preterm and term neonates (GA 24-42 weeks) and to understand the maturation in pharmacokinetic parameters along the whole neonatal age range. Using this model, we evaluated current bodyweight-based dosing regimens for their performance in preterm and term neonates and provide optimized dosing regimens.

\section{Methods}

\subsection{Study Population}

Fentanyl plasma concentration data originated from two datasets. The first dataset (dataset 1) originally included 83 mechanically ventilated patients in the hospital for children and adolescents, University of Helsinki, and was published as a noncompartmental pharmacokinetic study [6, 21]. During data processing, ten patients without plasma samples were excluded. Four additional patients were excluded because their samples were all below the limit of quantification (BLOQ). One patient was excluded because of consecutive BLOQ samples during infusion, which can most likely be attributed to a sampling or documentation error. Two patients who had all samples collected during blood plasma exchange were removed. One sample had an implausibly high concentration $(8.8 \mu \mathrm{g} / \mathrm{L})$ during an infusion of $1 \mu \mathrm{g} /$ $\mathrm{kg} / \mathrm{h}$ (59 $\mathrm{h}$ after the start of the infusion; previous sample at $47 \mathrm{~h}$ was $3.14 \mu \mathrm{g} / \mathrm{L})$ and was also removed from the dataset. Remaining samples that were BLOQ (15.6\%) were substituted with half the value of lower limits of quantification (LLOQ) $(0.5 \mu \mathrm{g} / \mathrm{L})$. In the elimination phase, only the first BLOQ sample was replaced by $0.5 \mu \mathrm{g} / \mathrm{L}$ and the subsequent samples deleted [27]. Finally, dataset 1 contained 232 observations from 66 patients.

The second dataset (dataset 2) included 98 preterm infants who were treated preintubation or for analgosedation in four NICUs in the Netherlands (Erasmus MCSophia, Maxima Medical Center [Veldhoven], Maastricht University Medical Center, and Radboud University Medical Center [Nijmegen]), and was previously published (NL47409.078.14, MEC-2014-067, NCT02421068) [26]. One abnormal sample $(317 \mathrm{~h}$ after the end of the infusion when fentanyl concentration was still detected) was deleted, resulting in 98 patients with a total of 441 observations.

Combining the datasets resulted in a total of 673 observations from 164 patients. The characteristics of both final datasets are summarized in Table 1.

\subsection{Dosing and Sampling Schedule}

For dataset 1, all neonates were scheduled to receive an initial 1 -h infusion of $10.5 \mu \mathrm{g} / \mathrm{kg}$, followed by a continuous infusion at a median constant rate of $1.5 \mu \mathrm{g} / \mathrm{kg} / \mathrm{h}$ (interquartile range [IQR] 0.7-1.5) for a median duration of $58 \mathrm{~h}$ (IQR 37-82). A median of 2 (IQR 1-4) additional boluses of fentanyl $1.5 \mu \mathrm{g} / \mathrm{kg}$ were given to 11 of these patients. Arterial blood samples were drawn at 2, 12, 24, 48, and $60 \mathrm{~h}$ after the 
start of the infusion to capture the whole concentration-time curve [21].

For dataset 2, the attending physician determined the dosing schedule according to the treatment protocol (bolus doses ranged between 0.5 and $3 \mu \mathrm{g} / \mathrm{kg}$ for intubation and analgosedation, and continuous infusion ranged between 0.5 and $3 \mu \mathrm{g} / \mathrm{kg} / \mathrm{h}$ for analgosedation). The individual dosage was adjusted according to the severity of pain and registered pain scores. In total, 98 preterm infants received a total of 776 fentanyl doses as bolus and/or continuous infusion. Among them, 69 infants only received boluses, nine infants only received continuous infusion, and 20 of those infants received both bolus and infusion. The median dosage for boluses was $2.1 \mu \mathrm{g} / \mathrm{kg}$ (IQR 1.5-3.7) given in a median of 3 minutes (IQR 2-3). The median dosage for continuous infusion was $1.0 \mu \mathrm{g} / \mathrm{kg} / \mathrm{h}$ (IQR 1.0-2.0). The median duration of continuous infusion was $23 \mathrm{~h}$ (IQR 7-55) [26]. Blood samples were collected during routine care using scavenge sampling.

\subsection{Analytical Method}

The samples from dataset $1(0.5 \mathrm{~mL})$ were collected in an EDTA Microtainer ${ }^{\circledR}$ tube (BD, Franklin Lakes, NJ, USA) and were analyzed by radioimmunoassay. The LLOQ was $1 \mu \mathrm{g} / \mathrm{L}$ [21]. The numeric values of BLOQ samples were not reported by the laboratory and were therefore treated as mentioned. The samples from dataset 2 were also collected in an EDTA Microtainer ${ }^{\circledR}$ tube and were analyzed using liquid chromatography-tandem mass spectrometry assay. The LLOQ was $0.3 \mu \mathrm{g} / \mathrm{L}$. BLOQ values in dataset 2 were reported as their detected values and were used in this analysis [28].

\subsection{Population Pharmacokinetic Model Development}

A population pharmacokinetic model was developed using NONMEM V7.4.3 (ICON Development Solutions, Ellicott City, MD, USA), supported by Per-speaks-NONMEM 4.9.0, and interfaced by Pirana 2.9.9 (Certara). Processing and

Table 1 Summary of patient characteristics

\begin{tabular}{|c|c|c|c|}
\hline Characteristic & Dataset 1 [21] & Dataset 2 [26] & Combined dataset \\
\hline Subjects $(n)$ & 66 & 98 & 164 \\
\hline Male $(\%)$ & 68 & 57 & 61.6 \\
\hline GA (weeks) & $31.25(25.30-42.30)$ & $27.10(23.90-31.90)$ & $28.95(23.90-42.30)$ \\
\hline \multicolumn{4}{|l|}{ Gestational status $(n)$} \\
\hline Extreme preterm $(\mathrm{GA}<28$ weeks $)$ & 12 & 59 & 71 \\
\hline Very preterm to late preterm (GA $28-36$ weeks) & 42 & 39 & 81 \\
\hline Full term (GA 37-42 weeks) & 12 & 0 & 12 \\
\hline Birthweight (g) & $1632(760-4245)$ & $906(390-1905)$ & $1055(390-4245)$ \\
\hline Extreme preterm (GA < 28 weeks $)$ & $928(760-1200)$ & $830(390-1280)$ & $840(390-1280)$ \\
\hline Very preterm to late preterm (GA 28-36 weeks) & $1632(795-3260)$ & $1285(760-1905)$ & $1390(760-3260)$ \\
\hline Full-term (GA 37-42 weeks) & $3365(2770-4245)$ & - & $3365(2770-4245)$ \\
\hline Current bodyweight (at the start of treatment) $(\mathrm{g})$ & $1632(760-4245)$ & $986(390-2087)$ & $1165(390-4245)$ \\
\hline Extreme preterm (GA < 28 weeks) & $928(760-1200)$ & $854(390-2020)$ & $880(390-2020)$ \\
\hline Very preterm to late preterm (GA 28-36 weeks) & $1632(795-3260)$ & 1323 (760-2087) & $1425(760-3260)$ \\
\hline Full-term (GA 37-42 weeks) & $3365(2770-4245)$ & - & $3365(2770-4245)$ \\
\hline $\begin{array}{l}\text { Postnatal age by GA subgroup (at the start of treat- } \\
\text { ment) (days) }\end{array}$ & $0.46(0.06-7.43)$ & $4.5(0-68)$ & $1.1(0-68)$ \\
\hline Extreme preterm $(\mathrm{GA}<28$ weeks $)$ & $0.64(0.06-1.68)$ & $8(0-68)$ & $6(0-68)$ \\
\hline Very preterm to late preterm (GA $28-36$ weeks) & $0.44(0.09-7.43)$ & $2(0-40)$ & $1(0-40)$ \\
\hline Full term (GA 37-42 weeks) & $0.44(0.12-1.84)$ & - & $0.435(0.12-1.84)$ \\
\hline Sample number $(n)$ & 232 & 441 & 673 \\
\hline Samples per subjects $(n)$ & $4(1-5)$ & $4(1-20)$ & $4(1-20)$ \\
\hline Concentration $(\mu \mathrm{g} / \mathrm{L})$ & $1.8(0.5-6.2)$ & $0.52(0.003-8.85)$ & $1.14(0.003-8.85)$ \\
\hline Indications & Ventilation & Reintubation or analgosedation & - \\
\hline Sampling route & Arterial blood samples & Arterial and capillary blood samples & - \\
\hline
\end{tabular}

Data are shown as median (range), unless otherwise specified

$G A$ gestational age 
visualization of output from NONMEM were performed in R 4.0.2 (CRAN.R-project.org). Parameters were estimated using the first-order conditional estimation with interaction method.

Both one- and two-compartment models were tested as structural models. For the statistical model, the interindividual variability (IIV) of the model parameters was assumed to be log-normally distributed using Eq. 1 .

$P i=P_{p} \times e^{\eta_{i}}$

where $P i$ is the individual estimate for the $i$ th individual, $P_{\mathrm{p}}$ is the population parameter value for parameter $P$, and $\eta_{i}$ is the random variable for the $i$ th individual and was assumed to have a normal distribution with a mean of zero and a variance of $\omega^{2}$. For residual errors, we compared an additive, proportional, and combined additive and proportional error model. Objective function value (OFV) and goodness-of-fit plots were used for model selection. For hierarchical models, a drop of more than 6.63 in OFV $(p<0.01$; degrees of freedom $=1$ ) based on a likelihood ratio test was considered significant.

The following covariates were evaluated: BW, CW, GA, PNA, postmenstrual age (PMA), sex, and being small for gestational age (SGA). In dataset $1, \mathrm{CW}$ over the different treatment days was not reported and all samples were collected within the first week of age, so we assumed that $\mathrm{CW}$ was equal to BW. No subject had missing information, other than $\mathrm{CW}$, in dataset 1 . In case of missing $\mathrm{CW}$ information at a certain PNA in dataset 2, linear interpolation was used for $\mathrm{CW}$ between two existing $\mathrm{CW}$ measurements. For continuous covariates (BW, CW, GA, PNA, PMA), linear, power, and exponential functions were tested to describe the relationship between covariates and parameters. The impact of CW on parameters was also tested by a bodyweight-dependent exponent (BDE) function [29]. For categorical covariates (sex, SGA), additive shift models were tested. For highly correlated covariates, all plausible combinations (i.e., BW and PNA; GA and PNA; CW and PMA; CW and PNA; BW and PMA) in different aforementioned functions were tested beforehand to select the best one for each parameter. Doing so meant that highly correlated covariates were not included at the same time. These covariates or their combinations were kept, and other uncorrelated covariates (sex and SGA) were added in a stepwise manner. For the forward inclusion, a drop of more than 6.64 points in OFV was considered significant $(p<0.01)$; for the backward exclusion, an increase of more than 10.83 points in OFV was considered significant $(p<0.001)$. In addition to the significance, the decision to include a covariate was also based on goodness-of-fit plots split by different covariates, deviations of independent parameters from the typical mean (ETA) plots, and reduction in IIV on the parameter of interest.

\subsection{Model Evaluation}

Goodness-of-fit plots and normalized prediction distribution errors (NPDEs) based on 1000 simulations were used for model evaluation. Each observed concentration was compared with the simulated concentrations using the NPDE package in $\mathrm{R}$ [30]. Additionally, bootstrapping $(n=1000)$ was performed to assess the stability of the final model.

\subsection{Evaluation of Current Dosing Regimens}

Using the final model, simulations were performed to generate concentration-time profiles in typical patients with different BW and PNA. To generate $\mathrm{CW}$ at different PNA for neonates with different BW, CW was assumed to follow the percentage change from BW of the growth curves published by Anchieta et al. [31]. Because the growth curves only described the CW-PNA profiles of neonates up to BW $2499 \mathrm{~g}$, the percentage change in CW for neonates with BW 2251-2499 $\mathrm{g}$ was used for those with BW > $2499 \mathrm{~g}$ [31].

Dosing regimens used for simulation were taken from the clinical practice where the data were collected (see Sect. 2.2) and were in accordance with the recommendation of the Dutch Children's Formulary [32]. Regimen 1 was continuous infusion of $1 \mu \mathrm{g} / \mathrm{kg} / \mathrm{h}$ for 7 days. Regimen 2 was $2 \mu \mathrm{g} /$ $\mathrm{kg}$ bolus of fentanyl every $4 \mathrm{~h}$ for 2 days. Lastly, a dosage recommendation for continuous infusion was provided that aimed to achieve a comparable concentration between 0.6 and $1.2 \mu \mathrm{g} / \mathrm{L}$ across infants with different BW and PNA.

\section{Results}

\subsection{Population Pharmacokinetic Analysis and Model Evaluation}

The combined dataset was best described by a two-compartment structural model with first-order elimination. Separated combined additive and proportional error functions for the different datasets resulted in the best fit judged by the best goodness of fit and the lowest OFV.

In the covariate analysis, implementation of the combination of PNA and BW on clearance was superior to implementation of PMA $(\Delta \mathrm{OFV}=-91)$. The relationship between BW, PNA, and clearance was best described by a power function according to Eq. 2 .

$\mathrm{CL}_{i}=\mathrm{TVCL} \times{\frac{\mathrm{BW}_{i}}{1055}}^{1.57} \times\left(\mathrm{PNA}_{i}+0.01\right)^{0.502} \times e^{\eta_{i}}$,

where $\mathrm{CL}_{i}$ is the clearance in $\mathrm{L} / \mathrm{h}$ for individual $i$, TVCL is the typical value of clearance for a patient with BW $1055 \mathrm{~g}$ and PNA 0.99 days, and $\eta_{i}$ is the between-subject random 
effect on clearance of individual $i$. Fig. 1 shows how clearance changes with BW and PNA. For neonates with the same $\mathrm{BW}$, the clearance at 7,14, and 21 days of PNA is 2.66 -fold, 3.77 -fold, and 4.63-fold the value at 1 day, respectively. For the same PNA, clearance for a neonate with BW $2000 \mathrm{~g}$ is 2.77-fold the clearance with BW $1000 \mathrm{~g}$; BW $3000 \mathrm{~g}$ is 5.03fold the clearance of BW $1000 \mathrm{~g}$ (Fig. 1).

Central distribution volume (V1) was significantly influenced by $\mathrm{CW}$. However, linear, power, and exponential functions of $\mathrm{CW}$ were not able to fully describe its variability. Therefore, a BDE function [29] (Eq. 3) was used and yielded the lowest OFV and most optimal ETA plots $(p<0.01)$.

$V 1_{i}=\operatorname{TVV} 1 \times\left(\frac{\mathrm{CW}_{i}}{1165}\right)^{\mathrm{BDE}_{i}} \times e^{\eta_{i}}$ and $\mathrm{BDE}_{i}=L 1 \times\left(\frac{\mathrm{CW}_{i}}{1165}\right)^{M}$

where $V 1_{i}$ is the $V 1$ in liters for individual $i$, TVV1 is the typical value of $V 1$ for a patient with $\mathrm{CW} 1165 \mathrm{~g}, \mathrm{BDE}_{i}$ is the $\mathrm{BDE}$ for individual $i, \eta_{i}$ is the between-subject random effect on $V 1$ for individual $i, L 1$ is the intercept in the scaling exponent, and $M$ is the exponent that allows the scaling exponent to change with $\mathrm{CW}$. The relationship between BDE and $\mathrm{CW}$, and the relationship between $\mathrm{V} 1$ and $\mathrm{CW}$, is plotted in Fig. S1 in the electronic supplementary material (ESM).

After including the covariates, the IIV for clearance and V1 decreased from 74.5 and $82.3 \%$ to 44.4 and $45.6 \%$, respectively. The plots illustrating the IIV of clearance and V1 (ETA plots) versus covariates for both the structural model and the final model are shown in Fig. S2 in the ESM. The pharmacokinetic parameters of the final model are listed in Table 2. All parameter estimates had relative standard errors below $40 \%$.

The goodness-of-fit plots (Fig. 2) indicate that the final model adequately described fentanyl concentrations for the different GA groups. The goodness-of-fit plots for different datasets are provided in Fig. S3 in the ESM. The mean NPDE from the model-building dataset was 0.07 with a variance of 0.97 . These values were not significantly different from the expected mean of 0 and variance of 1 . No trend was observed in NPDEs when plotted against time after dose and individual predicted concentrations (Fig. S4 in the ESM). The bootstrap results (Table 2, convergence rate $80.3 \%$ ) underline the robustness of the final model. All bootstrap estimates were close to the parameter estimates of the final model. The final model NONMEM control stream is provided in the ESM.

\subsection{Model-Based Dosage Evaluations}

\subsubsection{Infusion Regimen}

Figure 3 shows the concentration-time profiles for neonates with different BW and different PNA at the start of infusion when an infusion of $1 \mu \mathrm{g} / \mathrm{kg} / \mathrm{h}$ is given. The figure shows that there is an obvious variation in concentration-time profile between neonates with different BW and different PNA. For
A

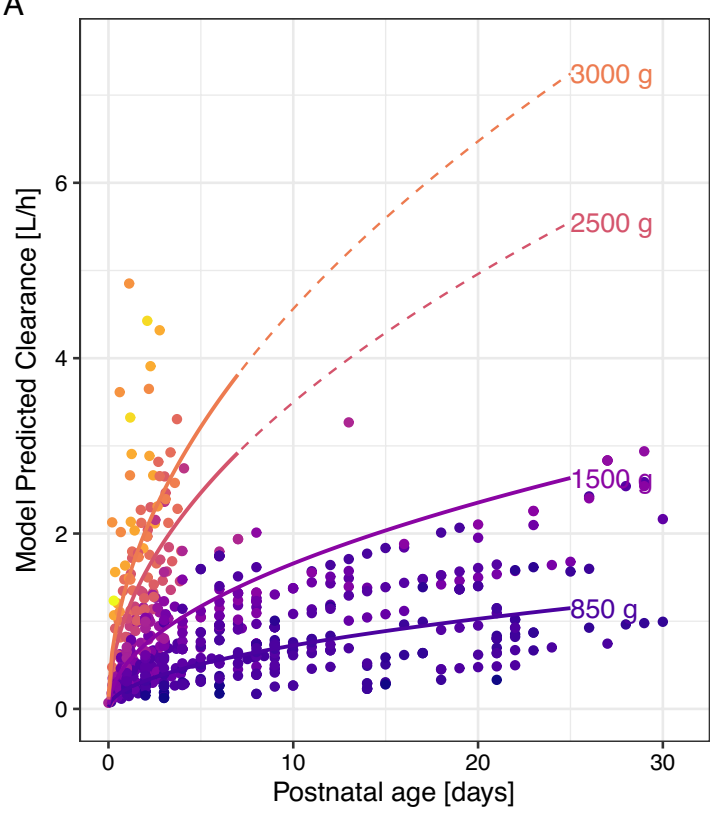

Fig. 1 A Clearance (L/h) vs. postnatal age (days) for the first 30 days of life, depicted as individual post hoc clearance (CL) values (dots) and population values (lines) for neonates with a birthweight of $850,1500,2500$, and $3000 \mathrm{~g}$. B Clearance $(\mathrm{L} / \mathrm{h} / \mathrm{kg})$ vs. postnatal age

B

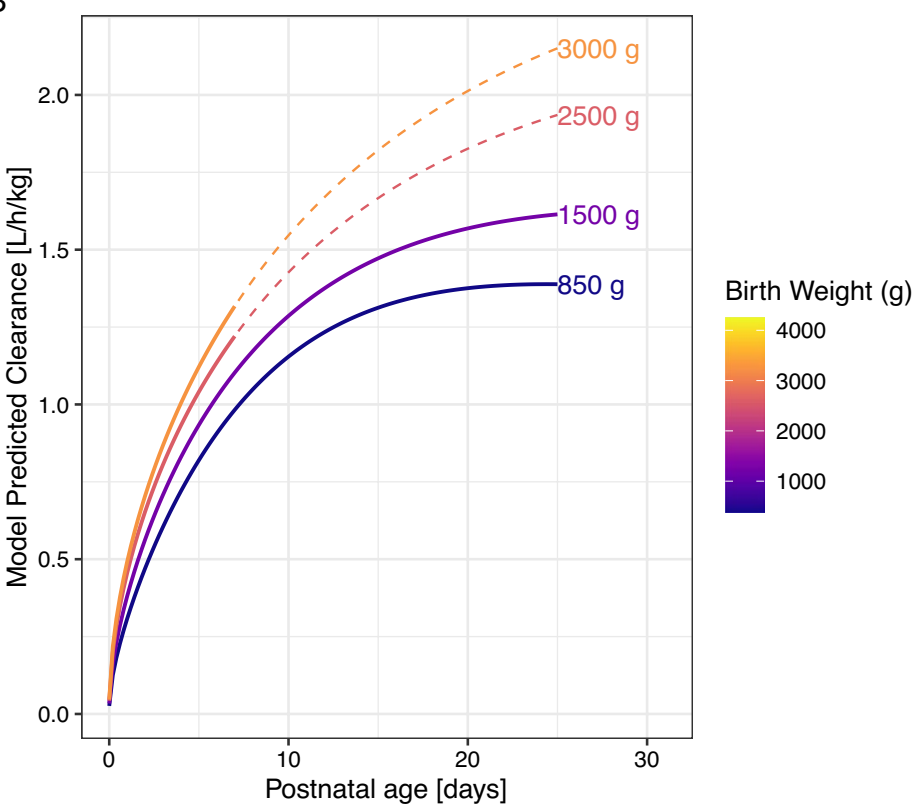

(days), depicted as population values (lines) for neonates with a birthweight of $850,1500,2500$, and $3000 \mathrm{~g}$. The dotted line means that we extrapolated clearance because of a lack of data for neonates beyond a birthweight of $2100 \mathrm{~g}$ and with a postnatal age beyond 1 week 
neonates with the same PNA, concentration decreases as BW increases (i.e., after $48 \mathrm{~h}$ of infusion, neonates with BW $850 \mathrm{~g}$ and PNA 0.5 day at the start of the infusion have a median concentration of $2.1 \mu \mathrm{g} / \mathrm{L}$, whereas it is $1.29 \mu \mathrm{g} / \mathrm{L}$ for neonates with BW $3000 \mathrm{~g}$ and PNA 0.5 days at the start of infusion). Within the same neonate, concentration decreases as PNA increases (i.e., neonates with BW $850 \mathrm{~g}$ and PNA 0.5 day at the start of the infusion have a median concentration of $2.1 \mu \mathrm{g} / \mathrm{L}$, whereas it is $0.68 \mu \mathrm{g} / \mathrm{L}$ for neonates with BW $850 \mathrm{~g}$ and PNA 21 days at the start of the infusion). For all neonates, the concentrations first increase until a "peak concentration" is reached, which then decreases over time as a result of increasing $\mathrm{CW}$ and PNA affecting the disposition. The time to reach peak concentration ranges from 12 to $48 \mathrm{~h}$ depending on BW and PNA, i.e., it takes around 48 $\mathrm{h}$ for a neonate with BW $850 \mathrm{~g}$ and PNA 0.5 days, whereas it only takes around $12 \mathrm{~h}$ for a neonate with BW $3000 \mathrm{~g}$ and PNA 21 days.

To prevent this variation as a result of BW and PNA, we propose a new PNA- and BW-adjusted dosing regimen. The details of this regimen are shown in Table 3. Figure 4 shows the concentration-time profiles of the proposed regimen. Comparable concentrations (0.6-1.2 $\mu \mathrm{g} / \mathrm{L}$ after $24 \mathrm{~h}$ of infusion) and area under the plasma concentration-time curve (at first day of infusion: $9-16 \mu \mathrm{g} \bullet \mathrm{h} / \mathrm{L}$; at 4th day of infusion:
12-26 $\mu \mathrm{g} \bullet \mathrm{h} / \mathrm{L}$; at 7 th day of infusion: $11-24 \mu \mathrm{g} \bullet \mathrm{h} / \mathrm{L})($ see Fig. S5 in the ESM) were achieved across the entire neonatal population in this study. We did not include neonates with $\mathrm{BW} \geq 2500 \mathrm{~g}$ and PNA $>7$ days in our dosage simulation because of a lack of data for this population.

\subsubsection{Bolus Regimen}

Figure 5A shows concentration-time profiles that can be expected upon intermittent bolus ( $2 \mu \mathrm{g} / \mathrm{kg}$ every $4 \mathrm{~h})$ dosing. Compared with the continuous infusion doses $(1 \mu \mathrm{g} / \mathrm{kg} / \mathrm{h})$, this regimen leads to a lower exposure as the daily dose is $12 \mu \mathrm{g} / \mathrm{kg}$ instead of $24 \mu \mathrm{g} / \mathrm{kg}$ for the continuous infusion. To provide rapid analgesia, Fig. 5B shows the concentration-time profiles for a loading dose of fentanyl $5 \mu \mathrm{g} / \mathrm{kg}$ to neonates with different BW and PNA. With this dose, a fentanyl concentration of around $0.75-1.2 \mu \mathrm{g} / \mathrm{L}$ is reached immediately in neonates with BW $850 \mathrm{~g}$, whereas the concentration is around $0.5 \mu \mathrm{g} / \mathrm{L}$ in larger neonates.

Table 2 Parameter estimates of the final model and bootstrap estimates

\begin{tabular}{|c|c|c|}
\hline Parameter & Final model estimate (RSE \%) & Bootstrap estimate $(95 \% \mathrm{CI})$ \\
\hline \multicolumn{3}{|l|}{ Fixed effects } \\
\hline \multicolumn{3}{|c|}{$\mathrm{CL}(\mathrm{L} / \mathrm{h})=\mathrm{TVCL} \times\left(\frac{\mathrm{BW}}{1055}\right)^{\theta_{\mathrm{BW}}} \times(\mathrm{PNA}+0.01)^{\theta_{\mathrm{PNA}}}$} \\
\hline TVCL & $0.31(10 \%)$ & $0.31(0.25-0.37)$ \\
\hline$\theta_{\mathrm{BW}}$ & $1.47(6 \%)$ & $1.47(1.30-1.69)$ \\
\hline$\theta_{\mathrm{PNA}}$ & $0.505(10 \%)$ & $0.505(0.403-0.630)$ \\
\hline \multicolumn{3}{|c|}{$V 1(\mathrm{~L})=\mathrm{TVV} 1 \times\left(\frac{\mathrm{CW}}{1165}\right)^{\mathrm{BDE}} \mathrm{BDE}=L 1 \times\left(\frac{\mathrm{CW}}{1165}\right)^{M}$} \\
\hline TVV1 & $10.6(7 \%)$ & $10.3(8.0-12.4)$ \\
\hline L1 & $1.56(10 \%)$ & $1.59(1.25-2.25)$ \\
\hline$M$ & $-0.417(32 \%)$ & $-0.447(-0.806$ to -0.190$)$ \\
\hline$Q(\mathrm{~L} / \mathrm{h})$ & $0.573(35 \%)$ & $0.60(0.26-3.63)$ \\
\hline$V 2(\mathrm{~L})$ & $3.37(23 \%)$ & $3.66(2.75-5.01)$ \\
\hline \multicolumn{3}{|c|}{ Interindividual variability [shrinkage \%] } \\
\hline On CL $(\%)$ & $44.4 \%(9 \%)[18 \%]$ & $43.7 \%(36.4-52.1)$ \\
\hline On V1 (\%) & $45.6 \%(13 \%)[30 \%]$ & $45.3 \%(32.8-58.9)$ \\
\hline \multicolumn{3}{|l|}{ Residual variability } \\
\hline Additive $(\mu \mathrm{g} / \mathrm{L})$ on dataset 1 & $0.246(27 \%)$ & $0.249(0.132-0.361)$ \\
\hline Proportional (\%) on dataset 1 & $0.23(12 \%)$ & $0.224(0.154-0.275)$ \\
\hline Additive $(\mu \mathrm{g} / \mathrm{L})$ on dataset 2 & $0.0297(26 \%)$ & $0.03(0.0059-0.0480)$ \\
\hline Proportional (\%) on dataset 2 & $0.361(8 \%)$ & $0.355(0.302-0.412)$ \\
\hline
\end{tabular}

$B D E$ bodyweight-dependent exponent, $B W$ birth weight (g), $C I$ confidence interval, $C L$ clearance $(\mathrm{L} / \mathrm{h}), C W$ current body weight $(\mathrm{g}), L 1$ the intercept in the scaling exponent, $M$ the exponent that allows the scaling exponent to change with current bodyweight, $P N A$ postnatal age (days), $Q$ intercompartment clearance $(\mathrm{L} / \mathrm{h}), R S E$ relative standard error, $T V C L$ the typical value for clearance $(\mathrm{L} / \mathrm{h}), T V V 1$ the typical value for central volume of distribution (L), V1 central volume of distribution (L), V2 volume of distribution of the peripheral compartment (L) 

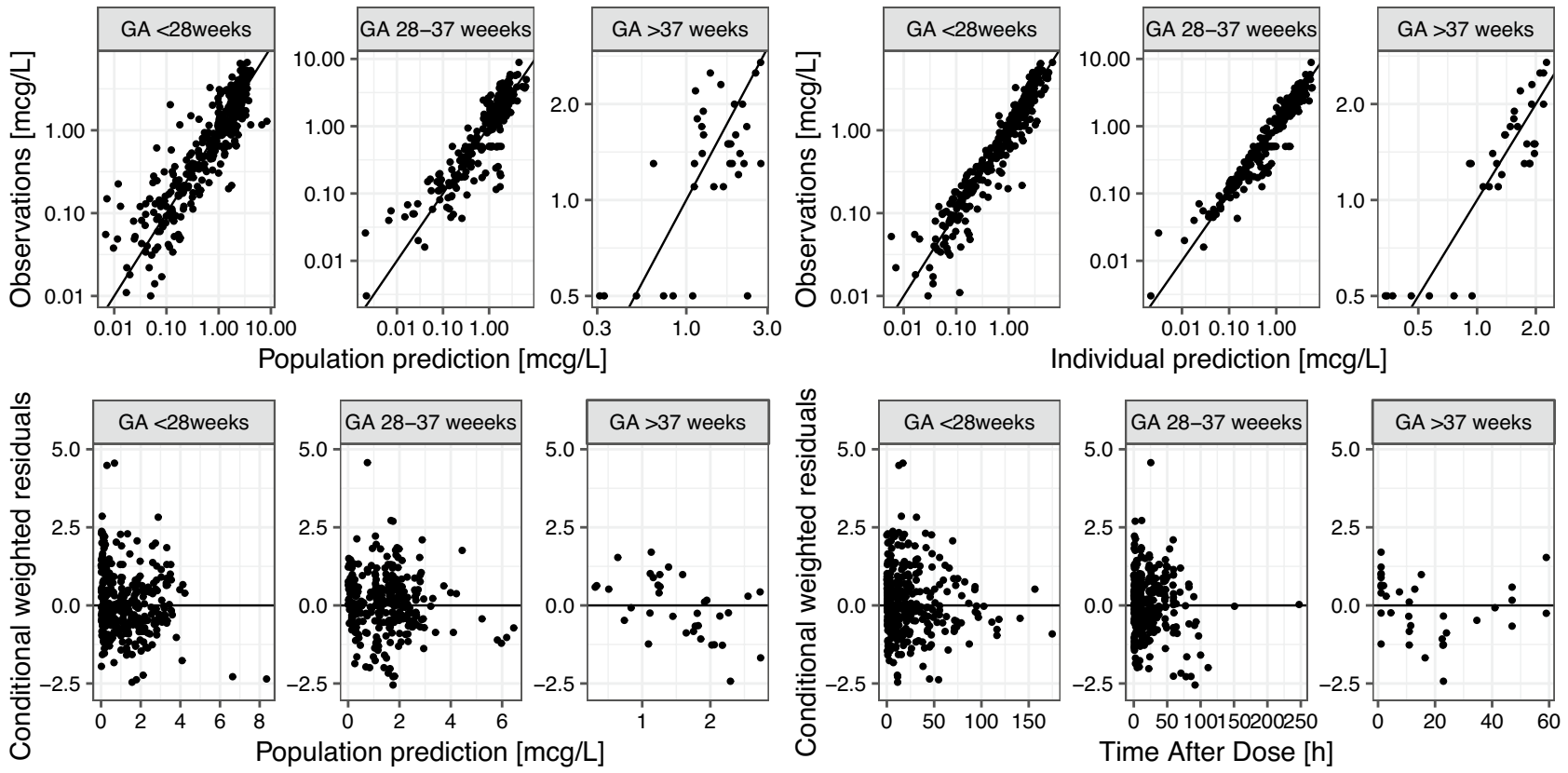

Fig. 2 Goodness-of-fit plot of final model grouped by gestational age (GA)

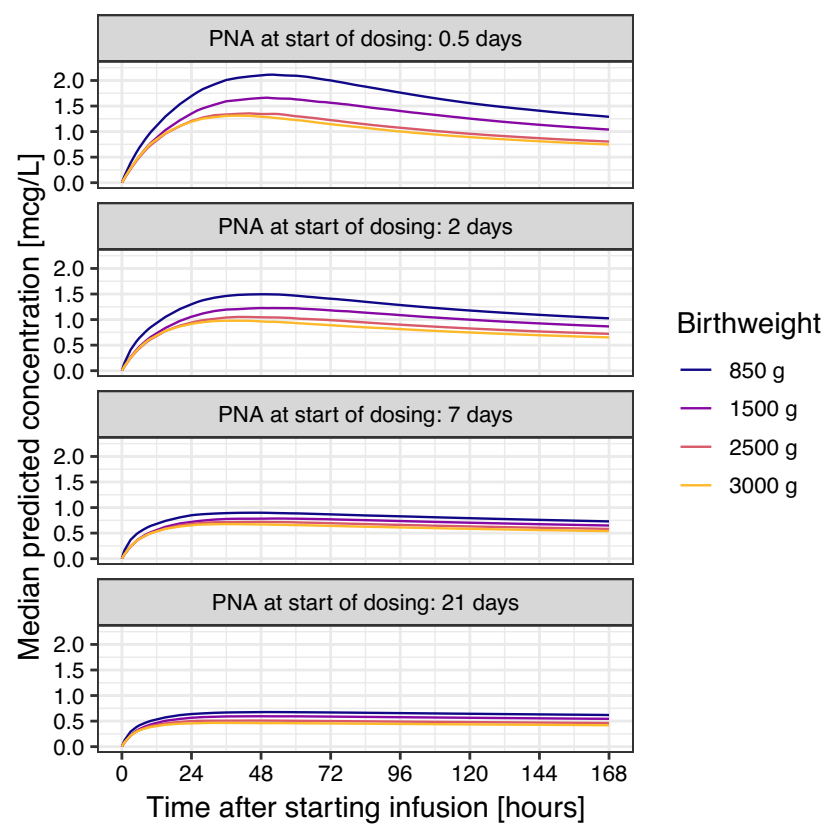

Fig. 3 Fentanyl concentration-time profiles $(n=1000)$ with each line representing the median for neonates with a birthweight of 850, 1500, 2500, and $3000 \mathrm{~g}$ at different postnatal age (PNA) at the start of a continuous infusion of $1 \mu \mathrm{g} / \mathrm{kg} / \mathrm{h}$ for 7 days

\section{Discussion}

We successfully developed a population pharmacokinetic model of fentanyl for neonates with GA 25-42 weeks.
Table 3 Proposed infusion regimens

\begin{tabular}{llll}
\hline Birthweight (g) & \multicolumn{2}{l}{$\begin{array}{l}\text { Postnatal age } \\
\text { (days) }\end{array}$} \\
\cline { 2 - 4 } & $1-2$ & $3-6$ & $\geq 7$ \\
\hline$<1500$ & 0.5 & 0.7 & 0.9 \\
$\geq 1500$ & 0.7 & 0.9 & 1.2 \\
\hline
\end{tabular}

Compared with previous neonatal studies [22, 33, 34], we had the largest number of samples and subjects with a wide range of GA and PNA. The population pharmacokinetic approach also allowed us to pool the samples of two datasets and clearly describe a large extent of the variability in fentanyl disposition. Fentanyl clearance showed a rapid maturation, which was best described by BW and PNA. The volume of distribution was described nonlinearly using a BDE function. This enabled us to evaluate the current dosing regimens and optimize the dosing of fentanyl in this vulnerable population, aiming at an equal exposure.

Combining BW and PNA as covariates on clearance was superior to PMA alone, suggesting that pre- and postnatal maturation separately influence clearance. The maturation of clearance could in part be a reflection of the increase in CYP3A4 activity in neonates, which is the main metabolizing enzyme of fentanyl. Both in vivo and in vitro studies showed that the activity of CYP3A4 is extremely low in the fetus and begins to increase after birth [35, 36]. However, as 


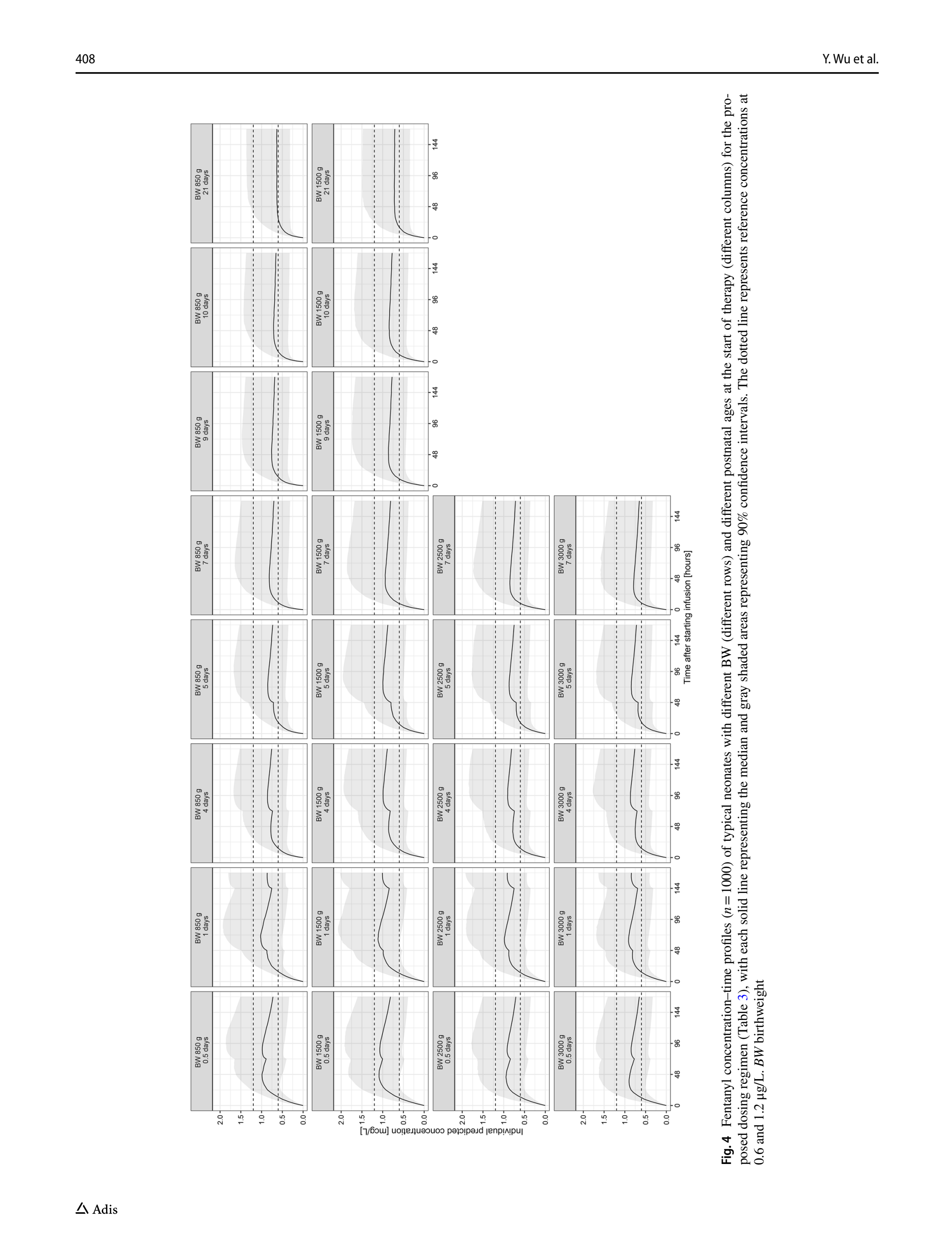


A

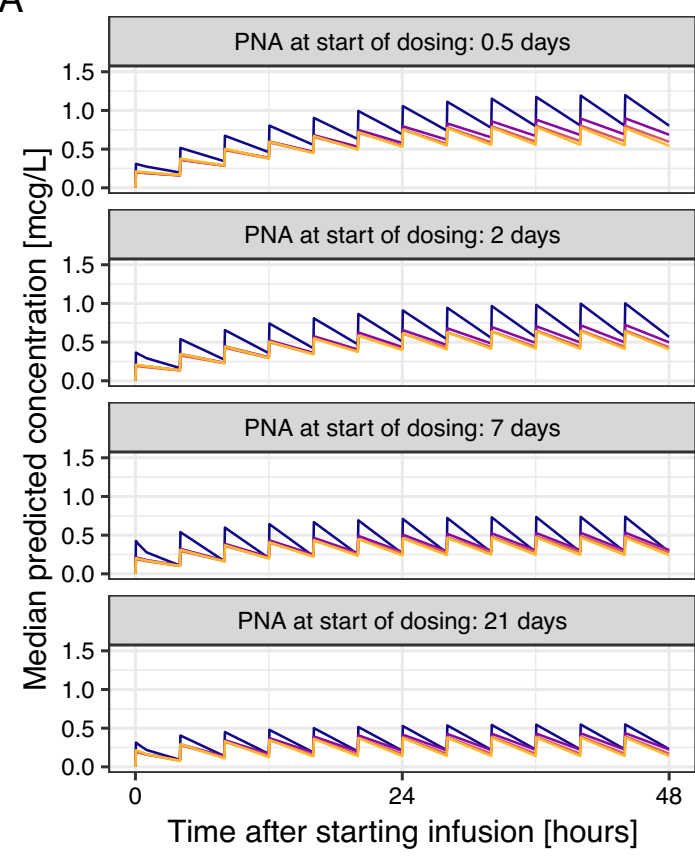

Fig. 5 Fentanyl concentration-time profiles $(n=1000)$ with each line representing the median for neonates with a birthweight of 850, 1500, 2500, and $3000 \mathrm{~g}$ at different postnatal ages (PNA) when given $2 \mu \mathrm{g} /$

CYP3A4 activity reportedly only reaches adult levels after 1 year of life, it seems that the CYP3A4 change alone cannot explain the fast maturation of fentanyl clearance observed in this study, i.e., for neonates with the same BW, clearance increased 2.7-fold from day 1 to day 7 of PNA. Instead, it seems likely that CYP3A7 is at least in part responsible for this rapid change because of its ability to metabolize drugs that are mainly metabolized by CYP3A4 in adults. CYP3A7 activity is maximal during the first week of life and declines progressively while CYP3A4 begins to take its place [13, 37]. In addition, pharmacokinetic studies have reported that lower hepatic blood flow could decrease fentanyl clearance $[33,34]$, suggesting a role for hepatic perfusion in fentanyl clearance in neonates. Hepatic blood flow in neonates increases with increasing cardiac output, whereas preterm neonates may have a lower hepatic blood flow because of a higher chance of a delayed closure of the ductus venosus than in term neonates $[38,39]$. Overall, the exact contribution of enzyme maturation versus liver blood flow is unknown, and more research is needed to identify the cause of the fast maturation of fentanyl clearance we observed in this study.

The remaining part of clearance variability $(44.4 \%)$ that could not be explained by BW and PNA could perhaps be caused by clinical conditions (such as inflammation [40] and abdominal surgery, which could lead to a decreased hepatic blood flow due to increased abdominal pressure [33, 34, $\mathrm{kg}$ per 4-h bolus A) and an initial loading dose $(5 \mu \mathrm{g} / \mathrm{kg}$ given in 3 min), followed by $2 \mu \mathrm{g} / \mathrm{kg}$ per 4 -h bolus (B)

41]), comedication (such as phenobarbital [42], a CYP3A4 enzyme inducer), and genetic polymorphisms. However, our study could not explore the potential relevance of these factors because of a lack of detailed relevant information.

Fentanyl is a highly lipophilic opioid that binds to both albumin and alfa-1-acid glycoprotein (AAG) [43, 44]. The bodyweight-normalized volume of distribution of fentanyl in this study (median $12 \mathrm{~L} / \mathrm{kg}$ ) was higher than that in adults $(3.2-5.9 \mathrm{~L} / \mathrm{kg}$ ) [45]. This may be attributed to the higher proportion of brain and central nervous system tissue in neonates than in adults [46]. In addition, neonates have a lower albumin and AAG level than adults [18, 23], which could lead to a higher unbound fentanyl fraction and thus higher distribution volume. To describe the variability of central distribution volume among neonates, we used a BDE function $[29,47]$. The exponent was found to vary between 1.66 for neonates with CW $1000 \mathrm{~g}$ and 1.05 for neonates with CW $3000 \mathrm{~g}$ (Fig. S1 in the ESM), indicating a quicker change in volume in lower bodyweight neonates. Possible explanations for this result can be the significant nonlinear increase of fat mass with bodyweight [48], as well as the fast change in organ size-including the central nervous system-in early life [20].

Our results showed that the use of a weight-based $1 \mu \mathrm{g} /$ $\mathrm{kg} / \mathrm{h}$ infusion regimen leads to a large variability in exposure among neonates (Fig. 3). This variability could even be larger given the unexplained variability in the real world. 
As the therapeutic range of fentanyl has not been defined, whether this variability in exposure could lead to side effects for some individuals or a lack of effect for others remains unclear. Previous related neonatal studies on the effects of fentanyl are sparse, and the results vary $[49,50]$. Although studies in adults receiving intravenous fentanyl for postoperative analgesia reported a mean analgesic concentration of $0.6-3 \mu \mathrm{g} / \mathrm{L}$ [45], the optimal analgesic concentration in neonates might differ. Neonates may be more sensitive to fentanyl because of the high unbound fraction [18] and a higher permeability of the blood-brain barrier [51], with the latter also potentially causing neonates to be prone to the respiratory-depressant effect of fentanyl [34]. Also, studies based on rat models suggested that rats might have a higher opioid receptor sensitivity during the first days of life [52].

In the absence of a target concentration, the PNA- and BW-based regimen suggested in this study (Table 3) was designed to maintain a comparable median concentration (0.6-1.2 $\mu \mathrm{g} / \mathrm{L}$ ) among all neonates (Fig. 4). This is within the IQR of the fentanyl concentration reported in our studies $(0.3-2.1 \mu \mathrm{g} / \mathrm{L})$ and within mean analgesic concentration $(0.6-3 \mu \mathrm{g} / \mathrm{L})$ reported in the aforementioned adult studies [45]. Given the long period of time needed to reach a steadystate concentration upon start of a continuous infusion, and the general desire for a quick response, (additional) loading doses should be considered in the first $24 \mathrm{~h}$ of treatment.

When fentanyl bolus administrations are used to provide rapid analgesia during repetitive painful procedures, the concentration based on the bolus regimen of $2 \mu \mathrm{g} / \mathrm{kg}$ per $4 \mathrm{~h}$ will be relatively low for first procedures (Fig. 5A). A higher loading dose at the start could therefore be considered. Figure 5B illustrates an immediate steady-state exposure upon a loading dose of fentanyl $5 \mu \mathrm{g} / \mathrm{kg}$ in neonates with different BW and PNA. In general, we recommend administering fentanyl $5 \mu \mathrm{g} / \mathrm{kg}$ in two separate doses with a dose interval of at least 5 minutes, as the highest recommended bolus dose in pediatric formularies is $3 \mu \mathrm{g} / \mathrm{kg}$ [32]. This would also avoid rapid administration, thereby preventing life-threatening side effects such as chest wall rigidity [8].

Our study has some limitations. First, it is important to realize that the maturation beyond 7 days of PNA in neonates born beyond 32 weeks may not be adequately described in our model because of the lack of data in that age group (Fig. 1). Therefore, the concentration and the clearance values of that group could be less accurate. Also, our study did not define other characteristics such as disease state and genetic polymorphisms that could further explain the variability in fentanyl pharmacokinetics. Furthermore, our target concentration may not be optimized for all neonates, and different types of pain likely require different fentanyl concentrations, e.g., procedure pain, prolonged pain, and extremely painful situations such as necrotizing enterocolitis [10]. Therefore, the appropriate evaluation of effects in each patient and individualized treatment remain urgently required. In the meantime, target concentrations among neonates still need to be defined in future pharmacodynamic studies.

\section{Conclusion}

We quantified the influence of prenatal and postnatal maturation on fentanyl exposure in term and preterm newborns. Given the relevance of BW and PNA for clearance, these covariates should be considered for neonatal dosing. The common practice of bodyweight-based dosing results in varying concentrations over time, potentially leading to insufficient concentrations for procedural pain and accumulation of fentanyl and overexposure in neonates with low BW and low PNA. Consequently, we recommend a PNA- and BW-based dosage adjustment to achieve comparable fentanyl concentrations across neonates and also recommend additional loading doses to provide rapid analgesia in the first $24 \mathrm{~h}$ of treatment. These pharmacokinetic data can pave the way for subsequent pharmacodynamic studies based on similar exposures.

Supplementary Information The online version contains supplementary material available at https://doi.org/10.1007/s40262-021-01076-0.

Acknowledgements The authors thank Aline G.J. Engbers for reviewing the codes of this paper.

\section{Declarations}

Funding The DINO study and all accompanying research were funded by the Netherlands Organization for Health Research and Development ZonMw (Grant number 836011022). Yunjiao Wu is funded by the China Scholarship Council (Grant number 201907060018).

Conflicts of interest Yunjiao Wu, Swantje Völler, Robert B. Flint, Sinno H.P. Simons, Karel Allegaert, Vineta Fellman, and Catherijne A.J. Knibbe have no conflicts of interest that are directly relevant to the content of this article.

Availability of data and material Not applicable.

Ethics approval All the data were obtained from previous studies that were approved by the relevant ethics committees.

Consent for publication Not applicable.

Consent to participate Not applicable.

Code availability The model code is available within the ESM.

Author contributions YW was involved in the analysis and interpretation of data and drafting the manuscript. SV was involved in the study design, analysis and interpretation of data, and drafting the manuscript. RBF, SHPS, KA, and VF were involved in acquisition of data, study design, and interpretation of data. CAJK was involved in study design, 
analysis, interpretation of data, and drafting the manuscript. All authors were involved in revising the manuscript and provided final approval.

Open Access This article is licensed under a Creative Commons Attribution-NonCommercial 4.0 International License, which permits any non-commercial use, sharing, adaptation, distribution and reproduction in any medium or format, as long as you give appropriate credit to the original author(s) and the source, provide a link to the Creative Commons licence, and indicate if changes were made. The images or other third party material in this article are included in the article's Creative Commons licence, unless indicated otherwise in a credit line to the material. If material is not included in the article's Creative Commons licence and your intended use is not permitted by statutory regulation or exceeds the permitted use, you will need to obtain permission directly from the copyright holder. To view a copy of this licence, visit http://creativecommons.org/licenses/by-nc/4.0/.

\section{References}

1. Anand KJ. Consensus statement for the prevention and management of pain in the newborn. Arch Pediatr Adolesc Med. 2001;155(2):173-80.

2. Circumcision WE. The uniquely American medical enigma. Urol Clin N Am. 1985;12(1):123-32.

3. Anand KJS. Clinical importance of pain and stress in preterm neonates. Neonatology. 1998;73(1):1-9.

4. Vinall J, Miller SP, Bjornson BH, Fitzpatrick KP, Poskitt KJ, Brant $\mathrm{R}$, et al. Invasive procedures in preterm children: brain and cognitive development at school age. Pediatrics. 2014;133(3):412-21.

5. Grunau RE, Whitfield MF, Petrie-Thomas J, Synnes AR, Cepeda IL, Keidar A, et al. Neonatal pain, parenting stress and interaction, in relation to cognitive and motor development at 8 and 18 months in preterm infants. Pain. 2009;143(1-2):138-46.

6. Saarenmaa E, Huttunen P, Leppäluoto J, Meretoja O, Fellman $\mathrm{V}$. Advantages of fentanyl over morphine in analgesia for ventilated newborn infants after birth: a randomized trial. J Pediatr. 1999;134(2):144-50.

7. Anand KJ, Hall RW. Pharmacological therapy for analgesia and sedation in the newborn. Arch Dis Child Fetal Neonatal Ed. 2006;91(6):F448-53.

8. Pacifici GM. Clinical pharmacology of fentanyl in preterm infants. A review. Pediatr Neonatol. 2015;56(3):143-8.

9. Aranda JV, Carlo W, Hummel P, Thomas R, Lehr VT, Anand KJ. Analgesia and sedation during mechanical ventilation in neonates. Clin Ther. 2005;27(6):877-99.

10. Meesters NJ, van Dijk M, Knibbe CA, Keyzer-Dekker CM, Tibboel D, Simons SH. Infants operated on for necrotizing enterocolitis: towards evidence-based pain guidelines. Neonatology. 2016;110(3):190-7.

11. Lago P, Garetti E, Merazzi D, Pieragostini L, Ancora G, Pirelli A, et al. Guidelines for procedural pain in the newborn. Acta Paediatr. 2009;98(6):932-9.

12. Kearns GL, Abdel-Rahman SM, Alander SW, Blowey DL, Leeder JS, Kauffman RE. Developmental pharmacology-drug disposition, action, and therapy in infants and children. N Engl J Med. 2003;349(12):1157-67.

13. Van Donge T, Mian P, Tibboel D, Van Den Anker J, Allegaert K. Drug metabolism in early infancy: opioids as an illustration. Expert Opin Drug Metab Toxicol. 2018;14(3):287-301.

14. Kovar L, Weber A, Zemlin M, Kohl Y, Bals R, Meibohm B, et al. Physiologically-based pharmacokinetic (PBPK) modeling providing insights into fentanyl pharmacokinetics in adults and pediatric patients. Pharmaceutics. 2020;12(10):908.
15. Lacroix D, Sonnier M, Moncion A, Cheron G, Cresteil T. Expression of CYP3A in the human liver-evidence that the Shift between CYP3A7 and CYP3A4 occurs immediately after birth. Eur J Biochem. 1997;247(2):625-34.

16. Hines RN. Ontogeny of human hepatic cytochromes P450. J Biochem Mol Toxicol. 2007;21(4):169-75.

17. Gow PJ, Ghabrial H, Smallwood RA, Morgan DJ, Ching MS. Neonatal hepatic drug elimination. Pharmacol Toxicol. 2001;88(1):3-15.

18. McNamara PJ, Alcorn J. Protein binding predictions in infants. AAPS Pharm Sci. 2002;4(1):E4.

19. Salem F, Abduljalil K, Kamiyama Y, Rostami-Hodjegan A. Considering age variation when coining drugs as high versus low hepatic extraction ratio. Drug Metab Dispos. 2016;44(7):1099-102.

20. Allegaert K, van de Velde M, van den Anker J. Neonatal clinical pharmacology. Paediatr Anaesth. 2014;24(1):30-8.

21. Saarenmaa E, Neuvonen PJ, Fellman V. Gestational age and birth weight effects on plasma clearance of fentanyl in newborn infants. J Pediatr. 2000;136(6):767-70.

22. Santeiro ML, Christie J, Stromquist C, Torres BA, Markowsky SJ. Pharmacokinetics of continuous infusion fentanyl in newborns. $J$ Perinatol. 1997;17(2):135-9.

23. Ziesenitz VC, Vaughns JD, Koch G, Mikus G, van den Anker JN. Pharmacokinetics of fentanyl and its derivatives in children: a comprehensive review. Clin Pharmacokinet. 2018;57(2):125-49.

24. Krekels EHJ, van Hasselt JGC, van den Anker JN, Allegaert K, Tibboel D, Knibbe CAJ. Evidence-based drug treatment for special patient populations through model-based approaches. Eur J Pharm Sci. 2017;109s:S22-6.

25. De Cock RFW, Piana C, Krekels EHJ, Danhof M, Allegaert K, Knibbe CAJ. The role of population PK-PD modelling in paediatric clinical research. Eur J Clin Pharmacol. 2011;67(Suppl 1):5-16.

26. Völler S, Flint RB, Andriessen P, Allegaert K, Zimmermann LJI, Liem KD, et al. Rapidly maturing fentanyl clearance in preterm neonates. Arch Dis Child Fetal Neonatal Ed. 2019;104(6):F598.

27. Keizer RJ, Jansen RS, Rosing H, Thijssen B, Beijnen JH, Schellens JHM, et al. Incorporation of concentration data below the limit of quantification in population pharmacokinetic analyses. Pharmacol Res Perspect. 2015;3(2):e00131-e.

28. Flint RB, Bahmany S, van der Nagel BCH, Koch BCP. Simultaneous quantification of fentanyl, sufentanil, cefazolin, doxapram and keto-doxapram in plasma using liquid chromatography-tandem mass spectrometry. Biomed Chromatogr. 2018;32(10):e4290.

29. De Cock RF, Allegaert K, Brussee JM, Sherwin CM, Mulla H, de Hoog M, et al. Simultaneous pharmacokinetic modeling of gentamicin, tobramycin and vancomycin clearance from neonates to adults: towards a semi-physiological function for maturation in glomerular filtration. Pharm Res. 2014;31(10):2643-54.

30. Comets E, Brendel K, Mentré F. Computing normalised prediction distribution errors to evaluate nonlinear mixed-effect models: the npde add-on package for R. Comput Methods Programs Biomed. 2008;90(2):154-66.

31. Anchieta LM, Xavier CC, Colosimo EA, Souza MF. Weight of preterm newborns during the first twelve weeks of life. Braz J Med Biol Res. 2003;36(6):761-70.

32. Dutch Children's Formulary. https://www.kinderformularium.nl/ geneesmiddel/543/fentanyl-parenteraal. Accessed 2. Jul 2021.

33. Gauntlett IS, Fisher DM, Hertzka RE, Kuhls E, Spellman MJ, Rudolph C. Pharmacokinetics of fentanyl in neonatal humans and lambs: effects of age. Anesthesiology. 1988;69(5):683-7.

34. Koehntop DE, Rodman JH, Brundage DM, Hegland MG, Buckley JJ. Pharmacokinetics of fentanyl in neonates. Anesth Analg. 1986;65(3):227-32. 
35. Salem F, Johnson TN, Abduljalil K, Tucker GT, Rostami-Hodjegan A. A re-evaluation and validation of ontogeny functions for cytochrome P450 1A2 and 3A4 based on in vivo data. Clin Pharmacokinet. 2014;53(7):625-36.

36. Lacroix D, Sonnier M, Moncion A, Cheron G, Cresteil T. Expression of CYP3A in the human liver-evidence that the shift between CYP3A7 and CYP3A4 occurs immediately after birth. Eur J Biochem. 1997;247(2):625-34.

37. Alcorn J, McNamara PJ. Ontogeny of hepatic and renal systemic clearance pathways in infants: part I. Clin Pharmacokinet. 2002;41(12):959-98.

38. Fugelseth D, Lindemann R, Liestøl K, Kiserud T, Langslet A. Postnatal closure of ductus venosus in preterm infants $<$ or $=32$ week. An ultrasonographic study. Early Hum Dev. 1998;53(2):163-9.

39. Kondo M, Itoh S, Kunikata T, Kusaka T, Ozaki T, Isobe K, et al. Time of closure of ductus venosus in term and preterm neonates. Arch Dis Child Fetal Neonatal Ed. 2001;85(1):F57-9.

40. Vet NJ, Brussee JM, de Hoog M, Mooij MG, Verlaat CW, Jerchel IS, et al. Inflammation and organ failure severely affect midazolam clearance in critically ill children. Am J Respir Crit Care Med. 2016;194(1):58-66.

41. Masey SA, Koehler RC, Ruck JR, Pepple JM, Rogers MC, Traystman RJ. Effect of abdominal distension on central and regional hemodynamics in neonatal lambs. Pediatr Res. 1985;19(12):1244-9.

42. Favié LMA, Groenendaal F, van den Broek MPH, Rademaker CMA, de Haan TR, van Straaten HLM, et al. Phenobarbital, midazolam pharmacokinetics, effectiveness, and drug-drug interaction in asphyxiated neonates undergoing therapeutic hypothermia. Neonatology. 2019;116(2):154-62.

43. Schug SA, Ting S. Fentanyl formulations in the management of pain: an update. Drugs. 2017;77(7):747-63.
44. Bista SR, Haywood A, Hardy J, Lobb M, Tapuni A, Norris R. Protein binding of fentanyl and its metabolite nor-fentanyl in human plasma, albumin and $\alpha-1$ acid glycoprotein. Xenobiotica. 2015;45(3):207-12.

45. Peng PW, Sandler AN. A review of the use of fentanyl analgesia in the management of acute pain in adults. Anesthesiology. 1999;90(2):576-99.

46. Fernandez E, Perez R, Hernandez A, Tejada P, Arteta M, Ramos JT. Factors and mechanisms for pharmacokinetic differences between pediatric population and adults. Pharmaceutics. 2011;3(1):53-72.

47. Bartelink IH, Boelens JJ, Bredius RG, Egberts AC, Wang C, Bierings $\mathrm{MB}$, et al. Body weight-dependent pharmacokinetics of busulfan in paediatric haematopoietic stem cell transplantation patients: towards individualized dosing. Clin Pharmacokinet. 2012;51(5):331-45.

48. Koo WWK, Walters JC, Hockman EM. Body composition in human infants at birth and postnatally. J Nutr. 2000;130(9):2188-94.

49. Roth B, Schlünder C, Houben F, Günther M, Theisohn M. Analgesia and sedation in neonatal intensive care using fentanyl by continuous infusion. Dev Pharmacol Ther. 1991;17(3-4):121-7.

50. Abiramalatha T, Mathew SK, Mathew BS, Shabeer MP, Arulappan G, Kumar M, et al. Continuous infusion versus intermittent bolus doses of fentanyl for analgesia and sedation in neonates: an open-label randomised controlled trial. Arch Dis Child Fetal Neonatal Ed. 2019;104(4):F433-9.

51. Ku LC, Smith PB. Dosing in neonates: special considerations in physiology and trial design. Pediatr Res. 2015;77(1-1):2-9.

52. Nandi R, Fitzgerald M. Opioid analgesia in the newborn. Eur $\mathrm{J}$ Pain. 2005;9(2):105-8.

\section{Authors and Affiliations}

\section{Yunjiao Wu ${ }^{1}$. Swantje Völler ${ }^{1,2,3} \cdot$ Robert B. Flint $^{3,4} \cdot$ Sinno H. P. Simons ${ }^{3} \cdot$ Karel Allegaert $^{4,5} \cdot$ Vineta Fellman $^{6,7,8}$. Catherijne A. J. Knibbe ${ }^{1,3,9}$}

1 Systems Biomedicine and Pharmacology, Leiden Academic Centre for Drug Research (LACDR), Leiden University, Leiden, the Netherlands

2 Pharmacy, Leiden Academic Centre for Drug Research (LACDR), Leiden University, Leiden, the Netherlands

3 Department of Pediatrics, Division of Neonatology, Erasmus MC Sophia Children's Hospital, Rotterdam, the Netherlands

4 Department of Hospital Pharmacy, Erasmus University Medical Center, Rotterdam, the Netherlands
5 Departments of Development and Regeneration and Pharmaceutical and Pharmacological Sciences, KU Leuven, Leuven, Belgium

6 Department of Clinical Sciences, Lund, Pediatrics, Lund University, Lund, Sweden

7 Folkhälsan Research Center, Helsinki, Finland

8 Children's Hospital, University of Helsinki, Helsinki, Finland

9 Department of Clinical Pharmacy, St Antonius Hospital, Nieuwegein, the Netherlands 